\title{
RECENT ADVANCES IN OUTDOOR PERFORMANCE EVALUATION OF PV SYSTEMS
}

\author{
M. A. Quintana, D. L. King \\ J. E. Cannon, J. R. Woodworth \\ W. E. Boyson, N. P. Adams \\ D. E. Ellibee
}

\author{
Sandia National Laboratories \\ Albuquerque, NM, 87185-5800 \\ EG\&G Special Projects \\ Albuquerque Division
}

\begin{abstract}
Sandia's Photovoltaic Techology Laboratory (PTEL) routinely performs outdoor tests of a variety of onesun and concentrator PV modules. Our experience is that while outdoor testing has its own set of problems, it can produce results that are more directly applicable to "field" conditions than testing in solar simulators. We have recently improved both the hardware and software at the PTEL to improve our accuracy and to deal with the special set of problems encountered in outdoor testing. Improvements in hardware include a computer-controlled solar tracker that allows us to test arrays up to $21 \mathrm{~m}^{2}$ in size; infrared imaging of modules; and electronic loads that allow us to test components with outputs up to 1,800 watts. Improvements in software include real-time monitoring of data collection; a relational data base that has improved the reliability of test setups, operations and analyses; and a standardized reporting process that relates module performance to a number of environmental parameters.
\end{abstract}

Introduction

The Photovoltaic Technology Evaluation Laboratory (PTEL) at Sandia National Laboratories routinely measures electrical performance characteristics of a variety of one-sun and concentrator photovoltaic modules. Our experience suggests that more reliable and directly applicable measurements can be made outdoors - taking advantage of the good spectral content and uniform illumination provided by natural sunshine, real-world weather conditions and the actual thermal loading that occurs during continuous operation.

In order to make our outdoor measurements more valuable and more accessible to the PV community, we have chosen a total quality management approach to improving our facility. As a result we have implemented improvements which will increase our capability, increase the accuracy of our measurements, isolate the effects of a number of environmental

This work supported by the U. S. Department of Energy under contract DE-AC04-76DP00789 variables, and decrease the cost and turn-around time involved with testing. Specifically, we have recently added 1) a new computer controlled tracker, 2) new electronic loads with the capability of testing components with outputs up to 1,800 watts, 3 ) an IR camera used to look at module hot spots, 4) a new data collection and analysis system and 5) a new standardized reporting format. These recent additions will be discussed in the sections that follow.

\section{Solar Trackers}

We have recently added to the PTEL an azimuth/elevation solar tracker which was originally built by ARCO solar in 1985 and which was recently modified and refurbished by Advanced Thermal Systems (ATS). The tracker has an open "unistrut"TR mounting plane that can accomodate modules or arrays up to $21.5 \mathrm{~m}^{2}$ in size. The tracker is currently instrumented to take current, voltage and temperature measurements on six modules at a time as well as measuring the outputs from tracking error monitors, a reference cell and a precision spectral pryranometer. This tracker is pictured in figure 1 .

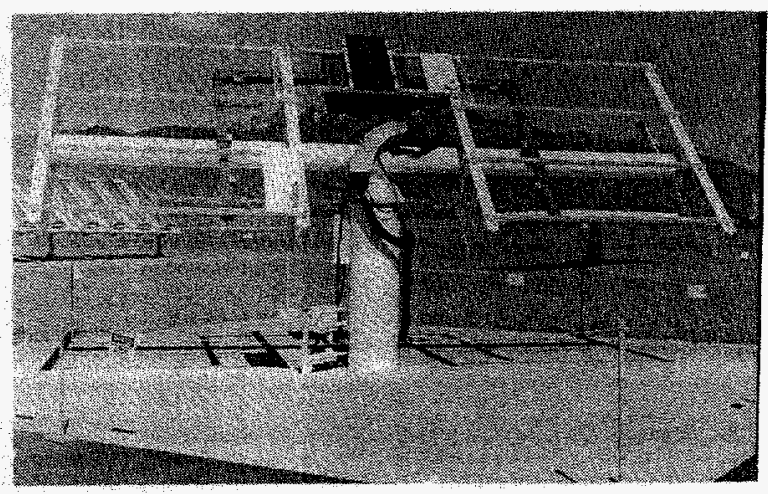

Figure 1: New computer-controlled ATS tracker at the PTEL. The tracker has a $21.5 \mathrm{~m}^{2}$ mounting plane and can test arrays with output powers up to 1,800 watts.

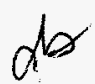

OISTRisution of THIS vocumEnT is UWLimita

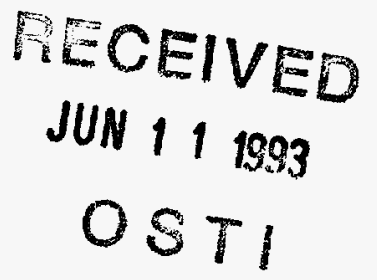




\section{DISCLAIMER}

Portions of this document may be illegible electronic image products. Images are produced from the best available original document. 
The tracker is driven by a Winsmith drive and $1 / 8$ horsepower DC motors. Tracker position is determined by a combination of reference position sensors and by counting motor turns with Hall effect transducers. The current version of the tracker control software, ATSUN, was developed by ATS and runs on an IBM-compatable PC. ATSUN determines the sun's position using time and date information in conjunction with an internal ephemeris program. ATSUN also allows for automated command sequencing, self-alignment of the tracker each morning, and a peak short-circuit-current tracking option developed specifically for testing PV modules. This tracker, which is currently undergoing final software corrections for slight mounting offsets, is expected to have a tracking accuracy of better than $0.1^{\circ}$ in both axes.

Although the ATS tracker has not yet completed its final alignment process, the utility of its automated command sequencing was demonstrated recently when we investigated the disagreement seen in the field between a precision spectral pyranometer and a reference cell. The ATS tracker was programmed to automatically step through a number of "off-track" angles while taking data on both instruments. The results, plotted in figure 2 , show that the instruments agree well at normal incidence, but differ at larger angles of incidence due to increased reflection from the glass cover on the reference cell.

The ATS tracker will be used in conjunction with an existing sun sensor-controlled tracker with a $17 \mathrm{~m}^{2}$ mounting plane to make most of our module performance measurements. Having two trackers available for measurements allows us to reduce turnaround time by readying modules for testing on one

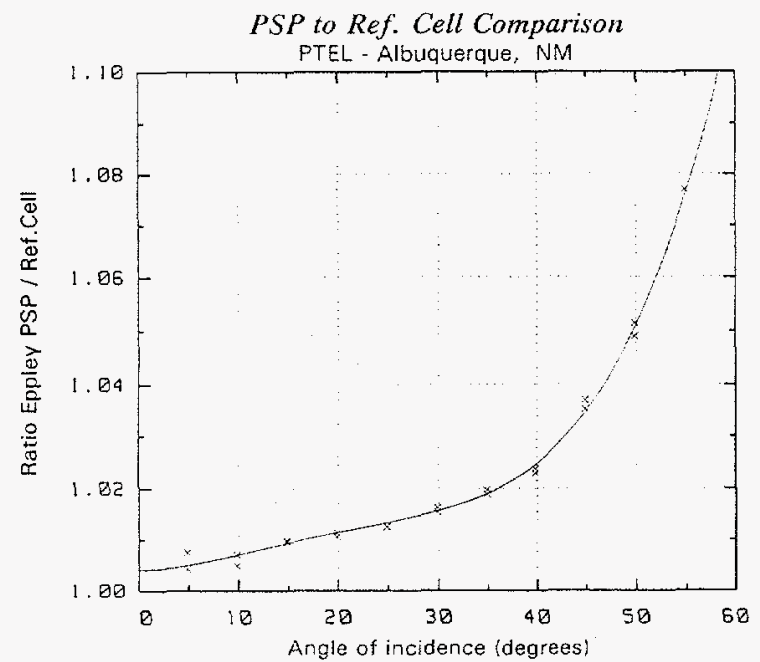

Figure 2: Calibration of reference cell versus precision spectral pyranometer as a function of the solar incidence angle. tracker while the other tracker is taking data. We have three other operational two-axis trackers, two of which are used for long-term exposure experiments and one of which is used for small component tests.

\section{IR Camera}

We now routinely use an Inframetrics Model 600 infrared imaging camera to assess module or component thermal behavior during electrical tests. This camera contains an imaging Mercury-Cadmium Telluride detector cooled to liquid-nitrogen temperature. The camera is sensitive to wavelengths from 3 to 12 microns and can record temperatures of objects from $-20^{\circ} \mathrm{C}$ to $+400^{\circ} \mathrm{C}$. Images from the camera are stored on video tape and then analyzed on a personal computer. The camera and its VCR are mounted on a small cart so that it can be easily be moved to the site of the test.

The camera's greatest value is its ability to provide (real-time) images of the temperature distribution across a PV module or component. Figure $\mathbf{3}$ shows a picture of the $20 \%$ efficient one-sun module manufactured by the University of New South Wales and a concentrator module manufactured by Solar Kinetics Inc. undergoing electrical testing at the PTEL. Figures 4 and 5 show IR images of the back planes of these two modules during testing. (The images are normally available in color, which shows up the thermal contours more dramatically than the black and white images shown here). In the UNSW module, slight electrical mismatches have caused several cells to operate 5 to $10^{\circ} \mathrm{C}$ hotter than the rest of the module. Temperatures are indicated in figures 4 and 5 for the points marked with cross-hairs. In the portion of the SKI module shown, the temperature of the aluminum backplane varies from about $39^{\circ} \mathrm{C}$ between cells to $51^{\circ} \mathrm{C}$ directly under cells. There is, however, very little variation in temperature from one cell to the next, indicating that the cells are well matched electrically. This thermal data was used to help validate a thermal transport code developed at Sandia for the SKI module. Figure 6 shows an IR image of a portion of the backplane of another concentrator module. This image clearly shows that two areas of the backplane are operating 30 to $40^{\circ} \mathrm{C}$ hotter than the rest of the module. This problem clearly limits the performance of the module, but it might have been missed by a test which used a few thermocouples on the back of the module to determine temperature. In a similar fashion, IR images of one-sun modules have revealed hot spots due to poor solder-bond contacts which appeared perfectly normal in the visible. 


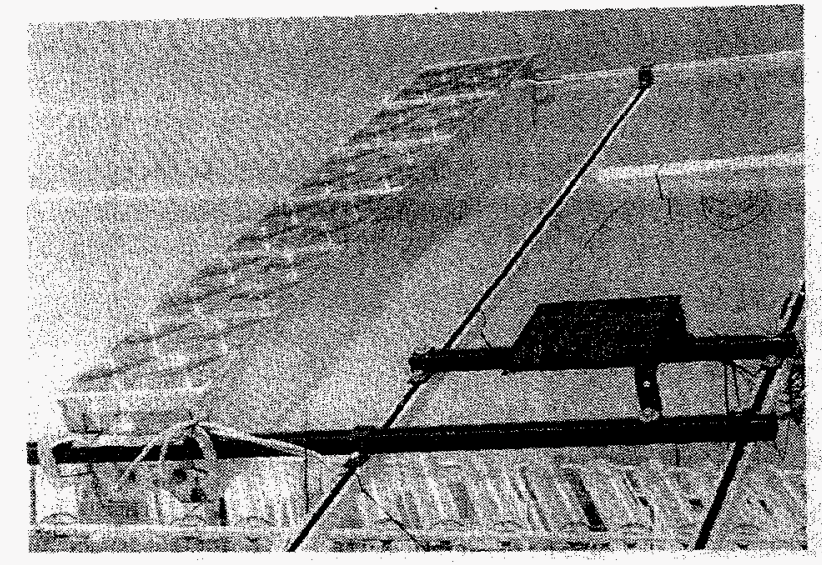

Figure 3: 20\% aperture-area efficient module from UNSW and SKI concentrator module undergoing electrical testing at Sandia's Photovoltaic Technology Evaluation Laboratory.

\section{UNSH 1993-2}

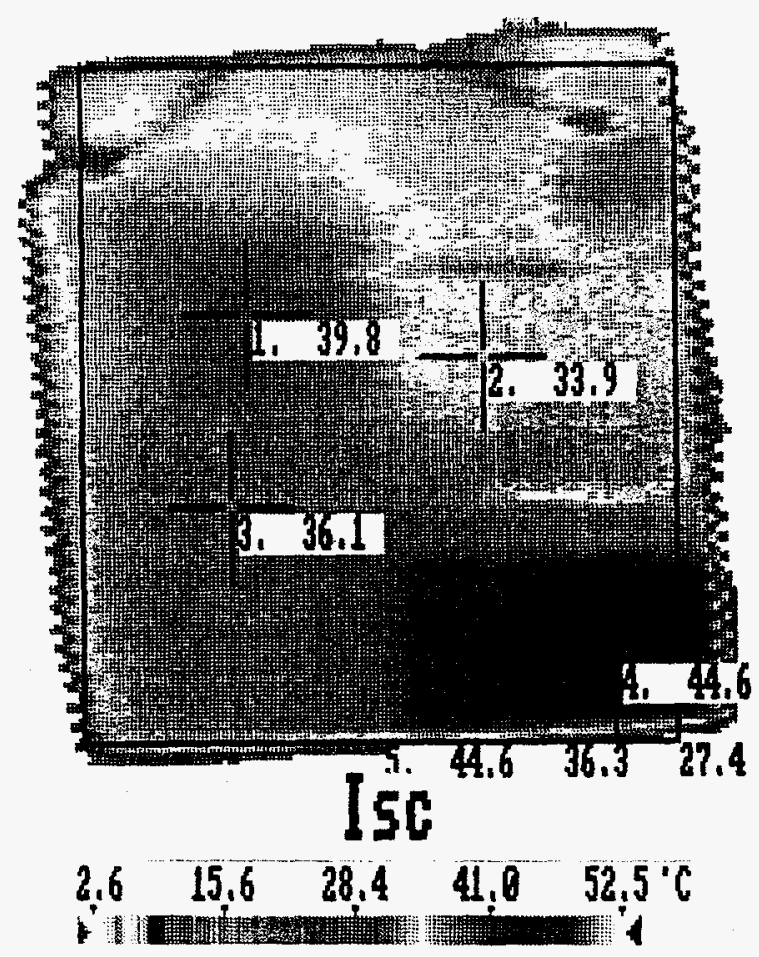

Figure 4: Black-and-white copy of color infrared image of UNSW module under short-circuit current conditions.

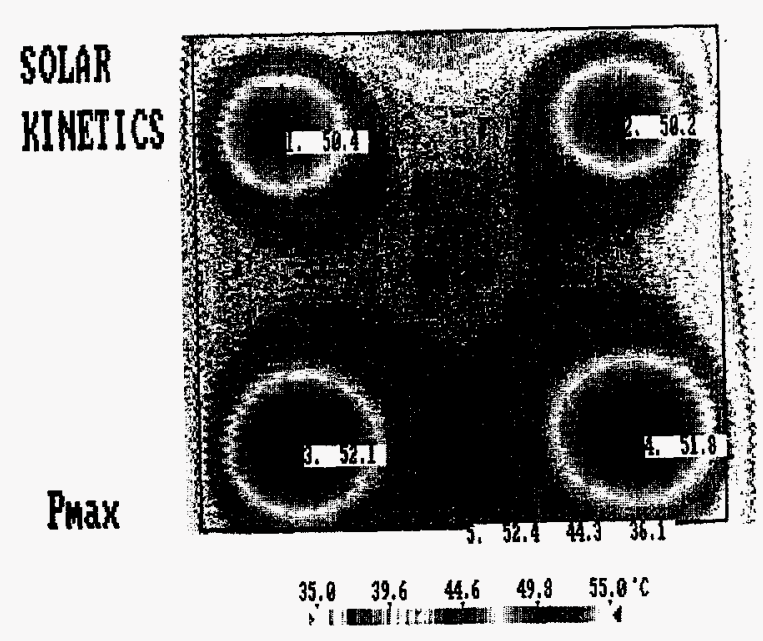

Figure 5: Infrared image of portion of SKI module backplane with module operating at maximum power during electrical testing.

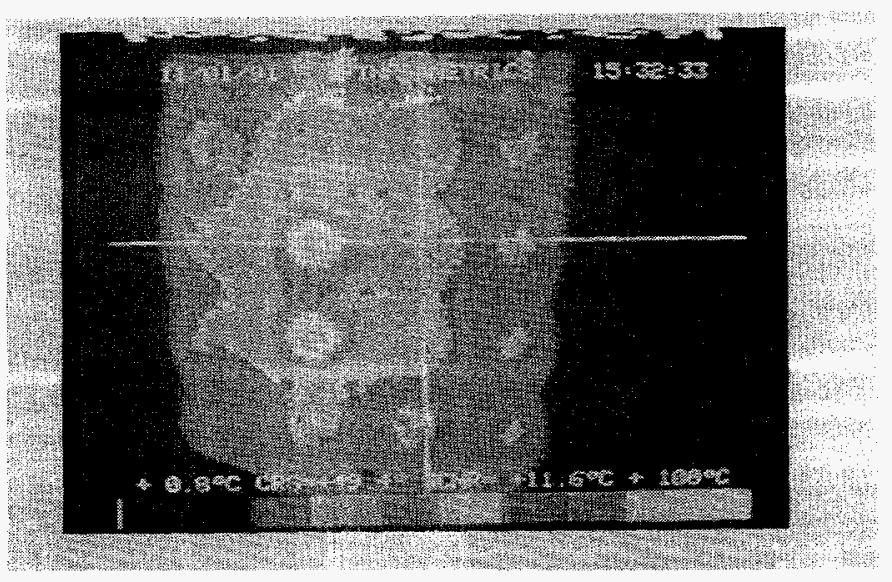

Figure 6: IR image of part of the backplane of a concentrator module with two areas operating $30^{\circ}$ to $40^{\circ} \mathrm{C}$ hotter than the rest of the module. Approximately 20 cell locations are included in this image.

\section{Data Collection and Analysis}

All of our module performance data is collected and analyzed on a Hewlett-Packard "UNIX" network with software written in HP's "Rocky Mountain Basic" programming language. In order to keep track of all the variables associated with each performance measurement, we have implemented a two-level database on the UNIX system. Level one contains 
values that are common to an entire performance test, such as module area, calibration status of detectors and cell temperature coefficients. Level two contains the observed performance parameters such as the maximum power output of the module, Voc and Isc. Level two also contains all of the environmental variables associated with each observed performance parameter, such as ambient temperature, wind speed, and irradiance data. Bringing all the data together in one database allows us to make the vital correlation between module performance and environmental parameters and also facilitates rapid and accurate data analysis.

In order to improve the reliability of our data, all measurements of module performance and irradiance are made on instruments whose calibrations are traceable to the National Institute of Standards and Technology (NIST). One-sun or concentrator module performance is related to the short-circuit current of reference cells calibrated at NIST for an air-mass 1.5 spectrum (global or direct). Broadband solar irradiance measurements are made with pyranometers and pyroheliometers calibrated using procedures consistent with ASTM standards.

The core of our data collection involves measurement of output current versus applied voltage for PV modules under test. In practice, a HP 6060-A electronic load automatically sets a sequence of voltages across the module and a digital multimeter measures the voltages and currents that result sweeping out a current-voltage (I-V) curve for the module. The HP loads are in modular units which can dissipate 300 or 600 watts of power. By paralleling these units, we can measure PV modules with outputs from 1 watt to 1,800 watts. Single PV cells are typically measured on a different data acquisition system, which can measure cells with outputs less than 0.1 watt.

Module electrical performance data can be collected on any one of four HP 300 data acquisition system (DAS) computers on the UNIX network, giving us the ability to take data on four PV modules or arrays simultaneously. The new software on this system allows flexibility in setting up different types of tests such as one-sun or concentrator modules, presents the $\mathrm{I}-\mathrm{V}$ and environmental data in real time, and gives user-selected alarms if any of the calibrations or environmental variables are out of predetermined ranges, Figure 7 shows a print-out of the monitor screen of one DAS during testing of the PV module recently evaluated for the University of New South Wales. The efficiency shown in Figure 7 is for the entire module area, including the mounting frame. Aperture-area efficiency for this module at standard test conditions $\left(1000 \mathrm{w} / \mathrm{m}^{2}, 25^{\circ} \mathrm{C}\right)$ was $20.5 \pm 0.4 \%$.

\section{Standard Data Analysis Package}

Since many of our tests and types of data analysis are
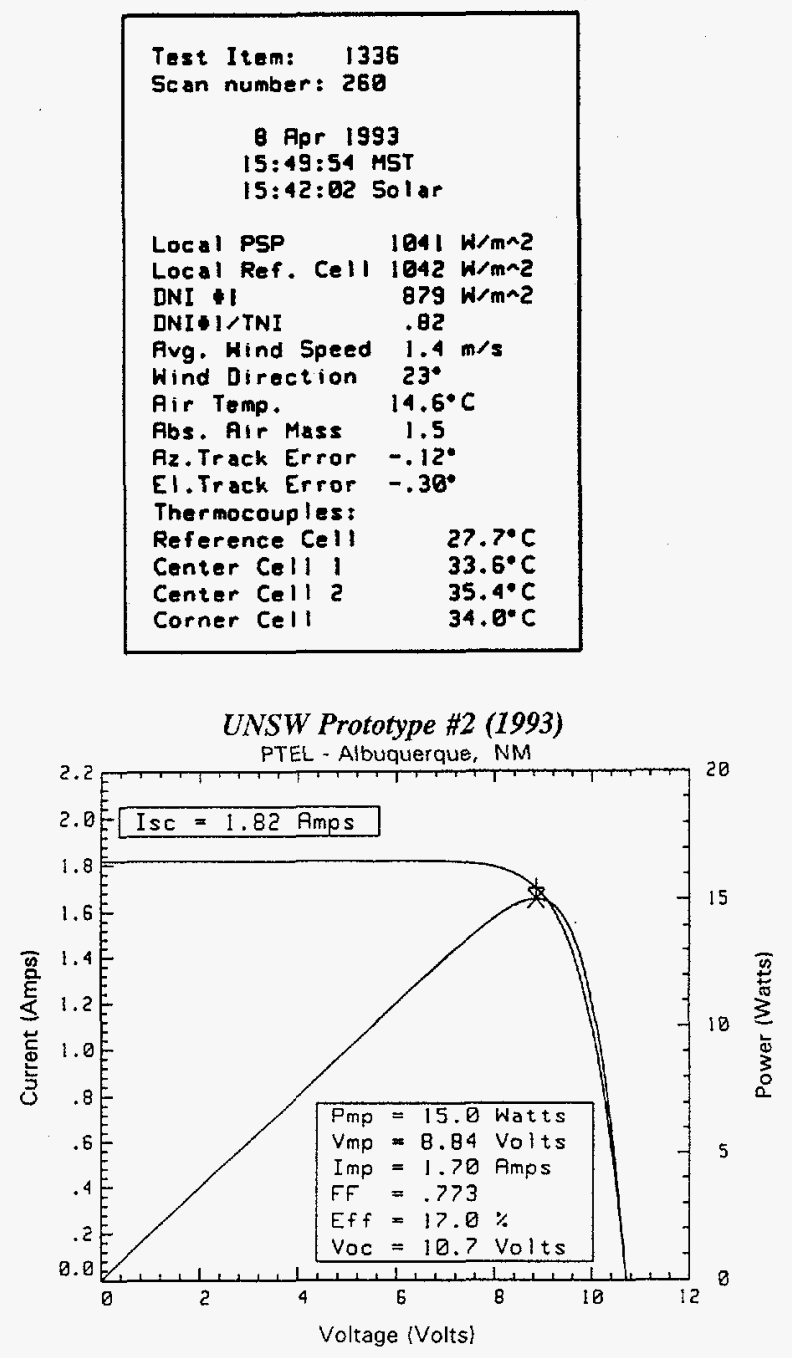

Figure 7: Print out of DAS monitor screen showing information available to operator during collection of module electrical data.

repetitive, we have developed software to automate the data analysis procedure. Before the standard data analysis package was implemented, limited analysis of the data took over 4 hours. With the standard data analysis package, analysis of the data is complete in $\sim 4$ minutes.

The analysis is divided into three segments, an automated preliminary report, data screening, and a final report. At the end of each session of data collection, the data analysis package will automatically produce a nine-page preliminary report. This report contains plots of performance variables, environmental variables, temperature variables and tracking variables. It also contains a test setup page, a page of 
definitions and a QA/QC page showing where the variable alarms were set for the test and calibration status of the instruments used in the test. Figure 8 shows several of the curves of module performance, environmental data and temperature data that are included in the preliminary report.

On the basis of the data in the preliminary report, the operator can choose the standard $3 \sigma$ screening of data or perform other screening as appropriate. After the data is screened, the analysis package will again produce the nine-page initial report on the screened data. Then, the analysis package will produce nine regression equations that express module performance as a function of solar irradiance, ambient temperature, calculated cell temperature, wind speed, and air mass. This correlation of module performance to environmental parameters is essential to the design of any $\mathrm{PV}$ system using the modules. The analysis package will then plot module performance as a function of several of the performance variables. A few samples of these regression relations and the performance plots associated with them for the UNSW module follow: Figures 9 and 10 show plots of module current and voltage versus irradiance and cell temperature respectively. The data and regression relations shown in figures 9 and 10 were used in figure 11 to display the module's maximum power output versus irradiance for different cell temperatures.

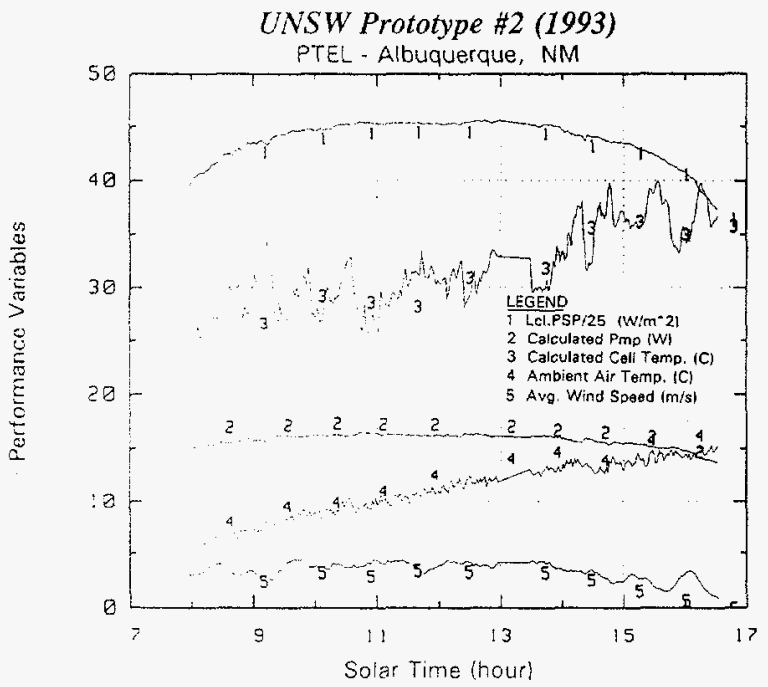

Figure 8: A plot from the first stage of data analysis for the UNSW module - graphs of maximum output power (Pmp), irradiance, cell temperature, ambient temperature and wind speed versus time.

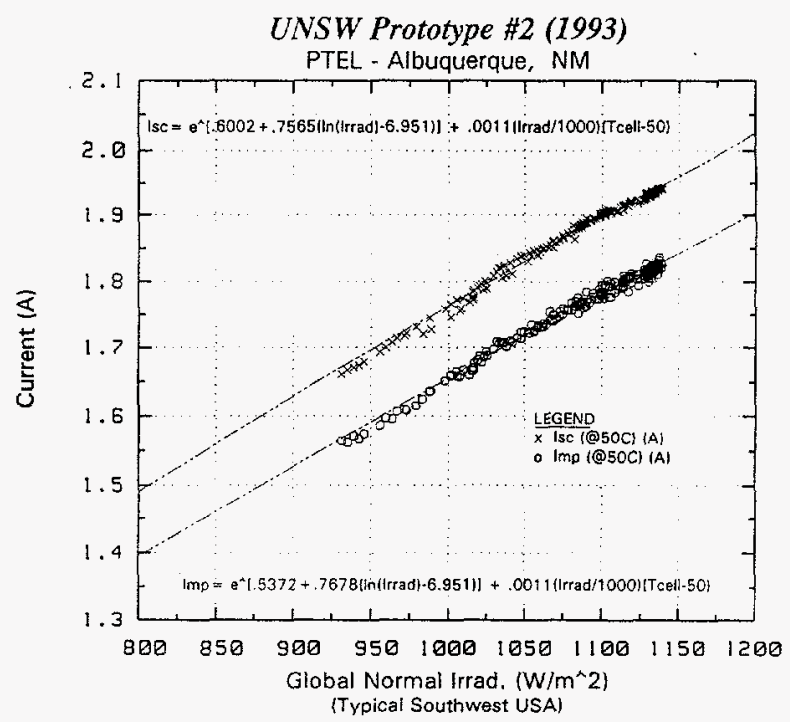

Figure 9: Graphs of short-circuit current (Isc) and maximum power current (Imp) for UNSW module corrected to a $50^{\circ} \mathrm{C}$ cell temperature and plotted as a function of global normal irradiance. The regression equations defining the lines though the data are also listed.

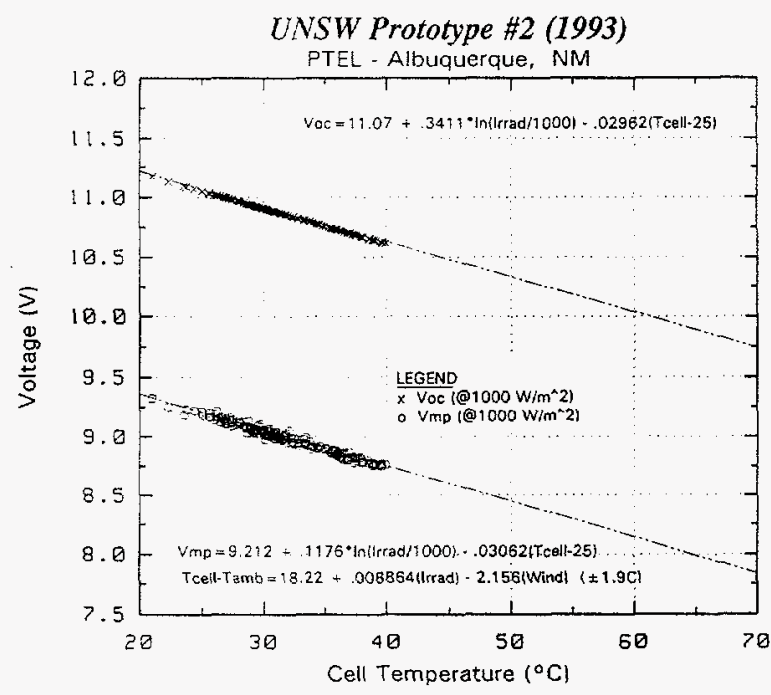

Figure 10: Graphs of open-circuit voltage (Voc) and maximum-power voltage (Vmp) corrected to a global normal irradiance of 1000 watts $/ \mathrm{m}^{2}$ and plotted as a function of cell temperature. The regression relations given fit the data well and enable calculation of Voc and Vmp for other conditions. 


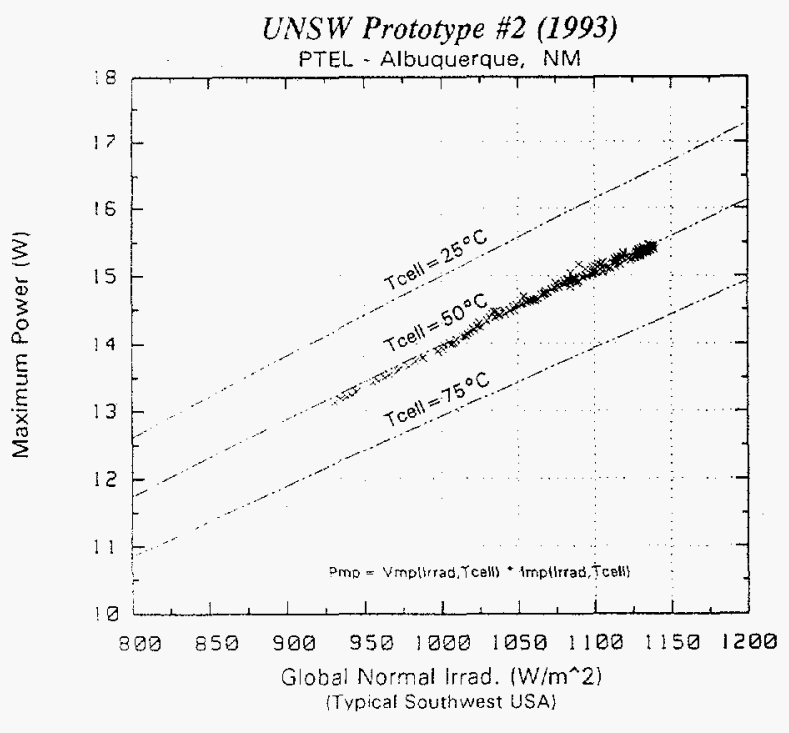

Figure 11: Graph of maximum output power (Pmp) of the UNSW module as a function of irradiance. Measured data is corrected to a cell temperature of $50^{\circ} \mathrm{C}$. Regression relation "fits" are shown for cell temperatures of $25^{\circ} \mathrm{C}, 50^{\circ} \mathrm{C}$, and $75^{\circ} \mathrm{C}$.

In addition to the plots of module performance, the analysis package produces tables describing module performance at a number of different test conditions. Examples of these test conditions are: Standard Test Conditions $\left(1000 \mathrm{w} / \mathrm{m}^{2}, 25^{\circ} \mathrm{C}\right.$ cell temp), PVUSA rating conditions $\left(850 \mathrm{w} / \mathrm{m}^{2} \mathrm{DNI}, 20^{\circ} \mathrm{C}\right.$ ambient, $1 \mathrm{~m} / \mathrm{s}$ wind speed), and "typical southwest conditions" (900 $w / \mathrm{m}^{2}, 50^{\circ} \mathrm{c}$ cell temp.).

Status

* By implementing a total quality management program that seeks to minimize all sources of error, we now routinely achieve accuracies of $\pm 1.5 \%$ in Isc, $\pm 2.5 \%$ in Pmax and $\pm 1.0 \%$ in Voc, with traceability to NIST.

* Sandia's testing capabilities now include performance testing for PV systems with outputs from 0.1 watt to 1,800 watts and availability of over $37 \mathrm{~m}^{2}$ of mounting surface on two 2 -axis trackers.

* Sandia's measured values of module performance are related through regression equations to DNI, TNI, ambient and cell temperature, air mass and wind speed, so that our measurements may be used to efficiently design systems using the modules we test.

* We now routinely perform infrared imaging of modules to check for hot spots due to problems such as mismatched cells, cell-to heat-sink delamination, or solder-bond problems.

* Additional capabilities at the PTEL that have not been discussed in this article include hail-ball impact testing, rain testing, wet and dry hipotential testing, thermal cycling, humidity-freeze testing and accelerated UV exposure.

* The PTEL's facilities have been used in the last year to perform 497 tests on 300 components for 20 PV manufacturers. In addition, over 1,000 people have toured the PTEL in the last year as part of our tech-transfer and educational outreach programs.

* Data analysis, which used to take over 4 hours, now takes 4 minutes with our standard data analysis package.

\section{DISCLAIMER}

This report was prepared as an account of work sponsored by an agency of the United States Government. Neither the United States Government nor any agency thereof, nor any of their employees, makes any warranty, express or implied, or assumes any legal liability or responsibility for the accuracy, completeness, or usefulness of any information, apparatus, product, or process disclosed, or represents that its use would not infringe privately owned rights. Reference herein to any specific commercial product, process, or service by trade name, trademark, manufacturer, or otherwise does not necessarily constitute or imply its endorsement, recommendation, or favoring by the United States Government or any agency thereof. The views and opinions of authors expressed herein do not necessarily state or reflect those of the United States Government or any agency thereof. 